\title{
História e literatura: uma relação de amor e ode em História do Brasil de Murilo Mendes
}

\author{
History and literature: a relationship of love and poetry \\ in História do Brasil by Murilo Mendes
}

Valmir de Souza

\section{Introdução}

Este estudo busca exercitar e pensar as interações de literatura e história. A história pode lidar com vários suportes e materiais, como fotografia, documentos, mapas etc. Um deles, que se constitui num dos mais produtivos e criativos, é a literatura. As relações entre história e literatura são complexas, tanto na teoria quanto nas práticas, e há necessidade de se explicitar as possibilidades de trabalho entre as duas áreas, tarefa que precisa ir além de uma análise da literatura somente em seus aspectos formais para abrir uma perspectivação mais colada

\footnotetext{
Valmir de Souza é doutor em teoria literária, professor adjunto da Universidade de Guarulhos e professor do Centro Universitário Unifig, em Guarulhos, SP (vsouza50@gmail.com).

Texto recebido em 17 de outubro de 2007 e aprovado para publicação em 11 de abril de 2008.

Nota do autor: Este artigo é parte de minha tese de doutorado (Souza, 2006). O texto foi revisto e sofreu mudanças e acréscimos. Agradeço aos pareceristas pela leitura atenta, e à minha companheira pelas indicações das análises dos poemas.
}

Estudos Históricos, Rio de Janeiro, vol. 21, nº 41, janeiro-junho de 2008, p. 45-58. 
na produção imaginária dos eventos históricos. Para acertar os ponteiros da história e da literatura vamos analisar as possíveis relações e interações entre esses campos.

Recentemente, Roger Chartier (2007:53), pesquisador renomado da área de história da leitura, afirmou a importância da literatura para o entendimento da história, referindo-se especificamente à "forma de atração" do romance histórico, que, se bem escrito, pode abranger um público amplo. Apesar de não abordarmos o gênero romance, vamos trabalhar com uma produção textual chamada "romance", constituída por poemas satíricos de Murilo Mendes (1901-1975).

Os problemas relacionados aos usos tanto do termo história como do termo literatura se referem ao estatuto de ambos os tipos de escrita. Em geral, são usos que se ligam a uma apropriação desses conceitos como "coisas" substancializadas, isto é, neles, cada termo possuiria um grau de autonomia absoluto, uma origem essencial e, portanto, intocável por ambas as partes, fato que os pesquisadores vêm tentando superar.

Os historiadores, em seus estudos, utilizam a literatura como documento, registro ou ilustração de fatos passados, e a literatura vem despertando interesse por ser considerada uma expressão que atribui outros sentidos aos eventos históricos.

No campo da história, as relações dos discursos literários e históricos foram possibilitadas pela problematização epistemológica situada na diferença entre a "passeidade" - o passado realmente acontecido - e a historiografia, ou "a narrativa feita dele" pelo historiador, "a sua recriação sob a forma de uma versão plausível". Junto com isso, firmou-se uma "convicção" de que os fatos passados não podem mais ser recuperados na sua concretude, sendo eles mesmos representações. Já no campo da literatura, observamos que as pesquisas são amplas e diversas, e vêm propiciando um olhar interdisciplinar, com o cruzamento de visões sobre a história e a literatura, superando assim a investigação literária pautada por uma prática de análise somente dos elementos intrínsecos da obra literária, sem associação com a sua produção histórica (Lemaire, 2000: 9-10).

Aqui não propomos uma divisão absoluta entre o discurso da história tradicionalmente ligado aos fatos - e a literatura, vista como produto único da imaginação, pois há uma infiltração mútua das duas formas de escrita: a ficção poética está eivada de elementos da história social, e esta se representa, diretamente ou de forma oblíqua, no texto poético. A escrita da história trabalha com elementos e técnicas de fabulação da realidade, enquanto a literatura ganha dimensões históricas (White, 1992; Gay, 1990). 
No parecer de Ria Lemaire (2000: 10), as duas escritas são bastante assemelhadas: "Tanto a narração literária quanto a historiografia pressupõem um processo e estratégias de organização da realidade, uma procura de uma coerência imaginada baseada na descoberta de laços e nexos, de relações e conexões entre os dados fornecidos pelo passado." Ambas as escritas fazem uma reconfiguração do passado. A história, ainda segundo a autora citada, promoveria um tipo de reconfiguração do passado "autorizada" pelas fontes e pela documentação, e calcada numa metodologia científica, enquanto a literatura "permite que o imaginário levante vôo mais livre e amplamente, que ele fuja, numa certa medida, aos condicionamentos impostos pela exigência da verificação pelas fontes" (Lemaire, 2000: 11).

Indo mais além no que se refere às relações entre história e literatura, Jacques Rancière (2005: 55-57) propõe a resolução da equação afirmando que a "soberania estética da literatura não é, portanto, o reino da ficção. É, ao contrário, um regime de indistinção tendencial entre a razão das ordenações descritivas e narrativas da ficção e as ordenações da descrição e interpretação dos fenômenos do mundo histórico e social". Buscando superar a divisão dos discursos das duas "histórias" (o da história e o da poesia), Rancière aborda a história como "sucessão empírica dos acontecimentos", em contraponto ao universo literário e sua "necessidade da ordenação poética". O autor aponta a possibilidade, devido à transformação estética, de a literatura e o testemunho histórico atuarem no mesmo campo de sentido. Para ele, "a evolução estética transforma radicalmente as coisas: o testemunho e a ficção pertencem a um mesmo regime de sentido (...)" (Rancière, 2005: 55-57). O “diálogo" da literatura com a história, portanto, é uma operação de corte do texto com a história, visto que esta, de certo modo, já está no texto literário.

A relação entre os dois campos, por ser intrínseca, pode ser formulada como história/literatura, equação mais adequada para se pensar o texto literário no cenário que estamos propondo, pois o núcleo principal dessa interação não está só nas condições de produção do texto literário, nem nas relações externas com os fatos, nem na presença destes na literatura, já que a poesia seria uma das formas de construção de sentidos históricos não explicitados pelos fatos (Bosi, 2002).

Mas é preciso lembrar que o escritor constrói sua literatura ancorado em parâmetros culturais definidos, ainda que suas fontes sejam negadas ou eclipsadas por uma dicção marcadamente individual e que, na elaboração sígnica, os eventos sociais sejam ressignifcados, obtendo sentidos não compartilhados por estudiosos da história - daí muito do conflito e da controvérsia relativa à primazia de um campo sobre outro. 


\section{Dois poemas do avesso em História do Brasil}

Murilo Mendes teve seus primeiros livros de poesia publicados nos anos 1930: Poemas (1930) e História do Brasil (1932). A publicação desta última obra, ainda que posterior à década de 1920, insere o poeta no contexto do primeiro momento modernista. Nela, o passado do país é reelaborado com base nas práticas satíricas da poesia do modernismo, atualizando o passado de forma singular, com uma reinterpretação da história que se vincula a uma compreensão do presente, e deixando perceber como a história ainda exerce papel fundamental nesses procedimentos poéticos.

O que pontuamos no estudo de Murilo Mendes é exatamente a sua tradução poética da história, pelo modo como articula tanto questões externas (voltadas para o passado), como questões de forma dos poemas, produzidos com grande audácia poética. Sua interpretação do passado é feita por contraste, fazendo perceber, através do riso, um outro movimento da história, mais denso e problemático, e construindo outras significações para os acontecimentos fortes através do tratamento poético dado à matéria histórica.

$\mathrm{Na}$ leveza de História do Brasil, se percebe uma tomada de posição bastante clara na perspectiva adotada, desvelando o que se oculta ao longo da história e traduzindo no campo poético o "ressentimento" social. A poesia, assim, produz uma visão de mundo contra o estabelecido pela história oficializada dos manuais, desmontando o imaginário histórico da vida nacional. Nessa obra, as vozes estão articuladas no sentido de promover um ataque às estruturas sociais tanto do passado como do presente. O poeta reage ao momento da Revolução de 30 e ao Governo Provisório, que se teriam esquecido de parte daqueles que apoiaram o movimento, isto é, os operários e os movimentos sociais (Fausto, 1985: 227-255).

Veremos a partir de agora o posicionamento poético do escritor em dois textos através dos quais ele "interfere" no campo da história. Os textos pertencem à série de poemas sobre as autoridades e se destacam pela sátira mordaz e pelo contraste com a historiografia mais tradicional da época. O primeiro desses textos, intitulado "Embarque do papagaio real", é um dos mais divertidos e ao mesmo tempo mais pungentes do livro. Nesse caso, considerando que alguns fatos são amplamente conhecidos, faremos uma análise estrutural do poema.

"Embarque do papagaio real"

Je suis pobre, pobre, pobre,

Je m'en vais d'aqui.

Esse tal de Napoleão 
Vem tomar conta da minha quinta,

Vem tomar minhas pipas de vinho,

Vem tomar meus p'rus,

Meus frangos,

Minhas galinhas d'Angola.

Tô fraco, tô fraco, tô fraco.

Vou-me embora, vou-me embora,

Vou chupar laranjas,

Vou comer minhas papas,

Vou gozar no Rio de pijama...

Se Carlota minha mulher deixar.

(Mendes, 1994 [1932]: 159)

O poema, em tom jocoso, refere-se ao episódio da vinda da família real para o Brasil. D. João VI é ridicularizado ao narrar sua fuga de Portugal motivada pela invasão de Napoleão. Pelo título, o governante é colocado no nível de uma ave ("papagaio real"), metáfora que indica uma situação subalterna logo na saída de Portugal. Essa mesma autoridade inicia o "relato" repetindo expressões da cultura francesa (“je suis"), tratando o invasor como "esse tal de Napoleão". A expressão francesa "je suis" funciona como ironia, pois é exatamente o francês quem está perseguindo o português. Sabe-se que a França não queria somente pegar "as riquezas" de Portugal (quinta, vinho, p'rus, frangos, galinhas...), mas tinha um plano estratégico maior no contexto do Bloqueio Continental de Napoleão.

O poema está estruturado com base no recurso da figura da repetição, figura esta que busca enfatizar algo e, no caso da poesia cômica, procura provocar o riso. Ao dar informações detalhadas sobre algo ou alguém, provoca um efeito de amplificação e enfatiza algum traço que poderia ser mais fraco. Ao mesmo tempo ela chama a atenção do leitor para determinado objeto. O princípio da repetição se dá em vários planos: pode haver variações sobre o tema ao longo do livro, com o uso de novos tons para a mesma matéria (Bergson, 2001: 88).

Na primeira estrofe já se evidencia o aspecto sonoro do poema, que se traduz nos procedimentos do papagaio falante, repetindo, no primeiro e último versos da estrofe, as expressões "je suis pobre" e "tô fraco". Esses sintagmas repetidos produzem uma mistura enfática da onomatopéia, figura de sonoridade que faz parte da configuração do poema e que aproxima o som do significado da coisa que o produz, o que evidencia a nivelação do rei com o papagaio.

Essa criatividade poética coloca-se a serviço da estratégia de rebaixar a personagem histórica, e isso é alcançado de modo eficiente e eficaz ao integrar a 
voz do rei a uma repetição do papagaio. Com isso, o uso do aparato verbal aproxima os dois pólos, o alto e o baixo, colocando-os no mesmo plano.

Ainda no aspecto sonoro, há uma figura de repetição que se junta à onomatopéia e se distribui pelos versos: a anáfora. O esquema anafórico é usado no sintagma verbal "vem tomar" e se desdobra nos versos que começam com pronomes ("Je suis", "Meus", "Minhas"), esquema que retorna na segunda estrofe ("Vou-me embora", "Vou chupar...") e reforça o movimento de fuga e de fragilidade. Essa debilidade do rei tem a ver com a França que viria tomar seus bens. Esse movimento de "enfraquecimento" repercute na mistura de dois tipos de aves: o papagaio e a galinha d'Angola. Na primeira estrofe temos no primeiro verso "Je suis pobre, pobre, pobre,", e no último, "Tô fraco, tô fraco, tô fraco." Isto é enfatizado quando o rei reproduz a língua francesa, com a expressão "Je suis...". Evidentemente essas expressões trazem um tom irônico, já que a família real não era nada pobre, e adquirem função estruturante no ataque realizado pelo poema.

A repetição de palavras e expressões tem a função de realçar o ridículo, arma comum aos poetas satíricos (Skinner, 2002; Bergson, 2001), com a reprodução da onomatopéia da "voz" do papagaio que não sabe falar, mas só repetir. $\mathrm{Na}$ repetição de expressões do tipo "Je suis pobre, pobre, pobre" ecoa a onomatopéia das aves incorporadas no texto; já "Vem tomar/Vem tomar/Vem tomar" são repetições anafóricas que enfatizam o ato da invasão do adversário. $\mathrm{O}$ repetir é idéia reforçada pela infantilização da personagem por meio da referência à cantiga infantil. Essa infantilização do rei pode ser constatada pelo uso de pronomes possessivos ("minha quinta", "minhas pipas" etc).

O poema se divide em duas estrofes, e essa divisão binária tem a ver com a transformação da ação das personagens. Por exemplo, as mudanças da pessoa verbal e do verbo "vir" para "ir" (ele vem para eu vou) indicam o movimento da invasão e da fuga. Veja-se que essa mudança se dá de uma estrofe para outra, sendo que as duas estrofes têm uma relação de causa e efeito, funcionando como seqüências de ação, isto é, na primeira temos o ato da invasão (Napoleão "vem tomar"), e na segunda o ato da fuga ("Vou-me embora").

Na segunda estrofe, com a idéia de fuga, comparece a idéia da facilidade que seria encontrada no Brasil, como se aqui fosse uma espécie de "paraíso", aliás, visão muito alimentada pelos relatos dos viajantes e muito comum na Europa. Também se enfatiza a idéia de que a família real não iria construir algo no Brasil, mas somente usufruir dos bens naturais e "gozar no Rio de pijama...". Mas, ao final, para retomar o tom de depreciamento, o governante precisa solicitar a autorização da mulher ("Se Carlota minha mulher deixar"), o que, para a época, soaria como sinal de fraqueza, já que o poder patriarcal era instituição social forte. Enfim, esse verso final arremata a falta de poder do "papagaio real". 
A figura da repetição leva à inversão que, ao colocar o mundo às avessas, tem a função de ridicularizar a imagem do poder. Por exemplo, o fato de a voz da autoridade ser emitida pela boca, ou melhor, pelo bico da ave, opera uma des-hierarquização do poder e uma inversão de papéis. Com isso, o escritor propõe a desestruturação da ordem através da linguagem paródica, indo do tom solene ao familiar, numa operação de transposição de um nível a outro com a intenção de $d e$ gradar a personalidade histórica.

Na continuidade desse tom de deboche, vejamos um outro poema, "Pescaria", pertencente à série de personalidades, que trata agora de Dom Pedro I e do famoso "Grito da Independência". Nesse caso, abordaremos as relações do poema com a pintura de Pedro Américo sobre a Independência, fazendo também referência ao "Hino Nacional", bem como ao "Hino da Independência".

"A pescaria"

Foi nas margens do Ipiranga,

Em meio a uma pescaria.

Sentindo-se mal, D. Pedro

- Comera demais cuscuz -

Desaperta a barriguilha

E grita, roxo de raiva:

"Ou me livro d'esta cólica

Ou morro d'ua vez!"

O príncipe se aliviou,

Sai no caminho cantando:

"Já me sinto independente.

Safa! vi perto a morte!

Vamos cair no fadinho

Pra celebrar o sucesso."

A Tuna de Coimbra surge

Com as guitarras afiadas,

Mas as mulatas dengosas

Do Club Flor do Abacate

Entram, firmes, no maxixe,

Abafam o fado com a voz,

Levantam, sorrindo, as pernas...

E a colônia brasileira

Toma a direção da farra.

(Mendes, 1994 [1932]: 164-165) 
O poema acima retoma o episódio bastante conhecido pela historiografia, fazendo uma reinterpretação política do gesto imperial inculcado pelos programas educacionais através de seus manuais de história "pátria". Faz-se aí um contraponto às várias formas de representação simbólica da história brasileira, entre elas a famosa tela Independência ou Morte!, de Pedro Américo (Fig. 1), bem como o Hino Nacional, que são produções mais ou menos referenciais, aceitas e até certo ponto reverenciadas por estudiosos e professores.

Veremos o que se passa no quadro e o que é "pintado" no poema referido. Passemos, então, a uma breve comparação entre as duas produções artísticas.

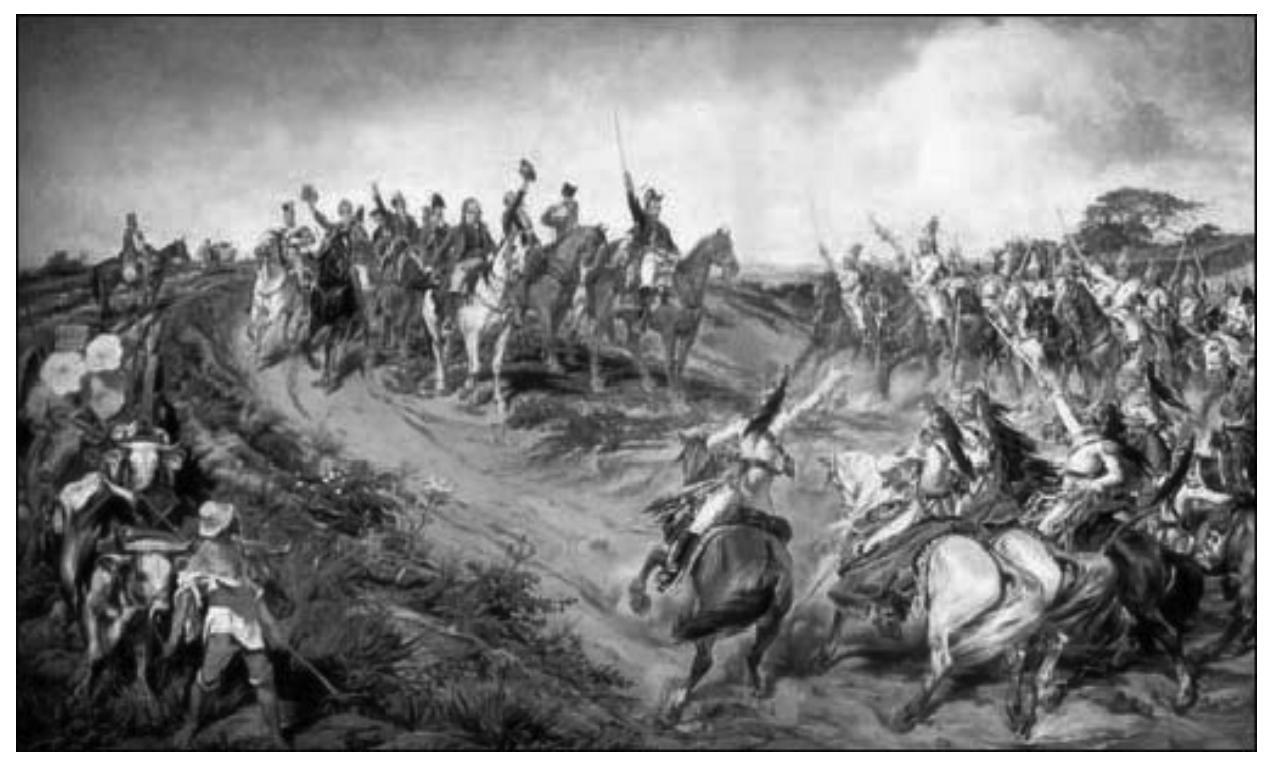

Fig. 1. Independência ou Morte!, Pedro Américo. Museu Paulista - USP. (7,60m x 4,15m)

A tela de Pedro Américo, pintada em Florença, na Itália, no período de 1886 a 1888, foi encomendada pelo governo de São Paulo para comemorar a Independência do Brasil, e se oferece como registro referencial de um evento histórico que marcou a trajetória do Império brasileiro (Oliveira, 2002: 66). Em 1888 , essa produção fez parte do rol de comemorações que vinham sendo engendradas durante o Império. O quadro tornou-se referência crucial na iconografia que aborda a independência, obscurecendo inclusive outras obras sobre o mesmo tema que vieram antes dele.

Essa imagem do artista paulista calou fundo no imaginário popular e também nas visões de intelectuais mais tradicionais do país, constituindo-se 
como parte integrante do patrimônio cultural nacional e desempenhando, como monumento público, papel importante na configuração de uma determinada visão da história do Brasil. Os monumentos (documentos, estátuas, livros etc.) sempre "jogaram peso decisivo na configuração da memória nacional no século XIX, pois expressavam a intenção deliberada, por parte de segmentos políticos definidos, de defender do movimento indeterminado da história fragmentos do passado reconstituídos por intermédio de abordagens e focos precisos" (Oliveira, 2002: 4). Por essas construções vemos a relação entre a política e a história nacional.

Como se sabe, as comemorações do Grito do Ipiranga não tiveram início imediatamente após o dia 7 de setembro de 1822, pois a instituição do Dia da Independência só iria se dar em 1826 (Oliveira, 2002: 2). Mas a imagem construída pelo artista traz equívocos históricos reconhecidos pelo próprio Pedro Américo que, em texto explicativo da composição de sua pintura, "O Brado do Ipiranga ou a Proclamação da Independência do Brasil”, afirma que não foram colocados na tela elementos e dados que poderiam comprometer a configuração do ato virtuoso do Imperador. Ainda segundo o pintor, não se sabe ao certo se a "Casa do Grito" existia no período da Independência e se o riacho do Ipiranga se localizava tão perto da Casa como aparece no quadro. A presença dos cavalos é duvidosa, e também o uniforme utilizado pela Guarda Nacional não existia na época. Diz o autor ter-se baseado em fontes orais e em crônicas sobre o ocorrido (In Oliveira, 1999: 11-31). Para dar a impressão de veracidade, o pintor realiza uma compactação imagética da história, reforçando o realismo histórico através dos detalhes a fim de promover uma visão idealista do evento, bem própria do gênero da pintura histórica.

Outra produção simbólica significativa como elemento cultuado da história nacional é o Hino Nacional. A composição permaneceu depois da República, pois a "manipulação do imaginário coletivo" pelos positivistas republicanos não conseguiu mudar o hino (Carvalho, 1990: 109 e 125). Só para relembrar, citemos os primeiros versos: "Ouviram do Ipiranga as margens plácidas / De um povo heróico o brado retumbante / E o sol da liberdade em raios fúlgidos / Brilhou no céu da pátria nesse instante" (grifo nosso).

O que acontece no poema de Murilo Mendes? Que visão informa o texto poético? A começar pelo título, vemos que o ato heróico do Imperador é deslocado para o mundo comezinho da "pescaria", prática das mais corriqueiras. Observa-se um rebaixamento do episódio consagrado pela concepção imperial, retratada com pompa no quadro de Pedro Américo. A representação oficial da história é colocada ao rés do chão, quando o poema desloca a magnitude do evento para o que há de mais “intestinal", isto é, a cólica de D. Pedro, que teria comido cuscuz. Esse deslocamento para as partes baixas reflete a intencionalidade do poeta no sentido de 
depreciar o poder instituído e uma certa visão sacralizante da história. Descrever e apelar para o nível baixo enfatiza o ponto de vista do poeta, que busca mostrar o ridículo das "invenções" da história nacional, em atitude bem ao gosto da sátira popular que não poupa o mundo da "alta cultura".

A sátira histórica realiza-se através do "desmanche" da figura imperial. Se a imagem do Imperador aparece estática, sobre o cavalo, como se fosse uma estátua eqüestre, em posição central e mais acima das outras personagens, o poema o pinta como um ser humano que, tendo necessidades vitais (comer e evacuar), não se configura de forma "dura" e paralisada como no quadro. Essa desestabilização da personalidade histórica é fundamental no texto literário.

Na versão do poema, o "grito" teria sido dado por força de um desarranjo intestinal causado por um tipo de comida, situando-se assim a história imperial no nível mais baixo, isto é, “excremental”. Aliás, o próprio Pedro Américo registra relato que afirma que D. Pedro realmente tivera um "incômodo gástrico" (In Oliveira, 1999: 11-31), o que coloca o texto literário mais de acordo com os fatos do que a pintura. Observe-se que após se livrar da cólica o príncipe "Sai no caminho cantando: "Já me sinto independente"'. A expressão mostra a referência que o poeta faz ao Hino da Independência, que D. Pedro teria composto no "calor da hora" (Infante, 2003: 262).

A proposta da autoridade é "cair no fadinho", prática musical portuguesa, mas a controvérsia se instala, pois contra o fado surge uma outra prática, o maxixe. Repercutem assim, no campo da linguagem poética, as contradições políticas entre os dois países. A música popular do Brasil, o maxixe, vence o fado, mostrando a força brasileira contra as práticas portuguesas (Infante, 2003: 262) e revelando a alegria das mulatas ("Levantam, sorrindo, as pernas"). Assim, para o poeta, a independência se vincula também à questão cultural, aliás, bem dentro do espírito modernista de redescoberta do Brasil através da pesquisa estética e da busca da cultura popular. A sobreposição de uma cultura à outra se dá, nesse caso, pelo fato de as mulatas entrarem "firmes" no maxixe, abafando o fado português.

Mais uma vez o poeta desenvolve uma divisão binária do texto. Na primeira parte expõe o ato heróico do príncipe e seu ridículo; já na segunda mostra a contraposição no campo da cultura, como demonstrado acima.

Nos versos finais do poema ("E a colônia brasileira/ Toma a direção da farra") faz-se uma inversão do que fora anunciado no começo de forma grandiosa ("Foi nas margens do Ipiranga"). Ou seja, sugere-se que o ato inicial se transformará numa "farra", indício de festa, mas também de descompromisso das classes dirigentes em relação aos destinos do país. Nesse sentido, para o poeta, essa Independência não pode ser levada a sério. 
A seriedade dos textos consagrados é tratada com deboche pelo escritor, o que denota um posicionamento ideológico assumidamente contra o establishment, pelo qual o poeta mostra as fissuras na elaboração de um dos "mitos fundadores" da história do país (Chauí, 2000: 9 e 10), realizando a iconoclastia do heroísmo imperial. Vale a pena ler o que o poeta, ainda em sua juventude, escreve sobre as personagens históricas do Brasil: "Geralmente, os heróis mais afamados são heróis de pacotilha; D. Pedro I, por exemplo, foi verdadeiro sultão; só cuidava das mulheres; desconhecia o seu país, julgando que o Brasil era uma sucursal da África" (Murilo Mendes, apud Guimarães, 1993: 35).

No poema concretiza-se, assim, a luta simbólica contra o "mito de origem" presente no quadro e no hino, que utilizam a informação histórica para montar um cenário heróico da nação. Produz-se um deslocamento para baixo no tratamento do episódio consagrado pela memória histórica e disseminado tanto pela tela de Pedro Américo quanto pelo Hino Nacional.

Nesse sentido, o trabalho com textos poéticos pode propor uma visão mais lúdica e mais crítica do país. Murilo Mendes, inconformado com o estado de coisas de seu tempo e com uma visão histórica fossilizada, propõe uma dessacralização dos "grandes eventos" através de uma prática de desconstrução dinâmica do passado.

A função da literatura estaria, então, na contramão das construções imaginárias realizadas em certos momentos históricos. Assim, podemos afirmar com Nicolau Sevcenko (2003: 29) que a ética da criação literária traria em seu interior mais o intuito de transformação do que a permanência do status quo. E por estar na ordem do desejável, essa criação estaria mais voltada para o devir do que para o estado atual das coisas.

Assim, pensar no passado deve nos levar a organizar os materiais historiográficos para nos orientarmos no presente, mas não de forma estática, como se a história fosse uma imagem pertencente ao passado. Como afirma Schorske (2000: 13), "podemos também 'pensar com a história' de outro modo, quando concebemos a história como processo. Então a história é dinâmica, ligando ou dissolvendo elementos estáticos num padrão narrativo de mudança".

A literatura como produção histórica e social pode proporcionar uma visão mais dinâmica da realidade histórica. Para Sevcenko (2003: 29 e 30), a produção literária não estaria só pautada pela factualidade, mas voltar-se-ia para a esfera do vir-a-ser, o que a coloca numa dimensão "transcendente" em relação à história. Esta, no entanto, apresentaria ao escritor os modos de significação em situações que ele não controla, criando assim uma relação tensa entre os dois modos de representar a história social. Em relação à ficção, a história teria a liberdade de narrar "sobre as possibilidades que não vingaram, sobre os planos que não se concretizaram. Ela é o testemunho triste, porém sublime, dos homens que foram 
vencidos pelos fatos". No contraponto ao culto dos fatos, a literatura manifestaria não só o aspecto comunicativo, mas também a dimensão utópica da linguagem, no sentido de projetar outras realidades possíveis, sem se subordinar às necessidades factuais do discurso histórico.

Como aponta Murilo Marcondes de Moura (1998: 180), "a poesia, como expressão das mais arcaicas e densas da experiência humana, pode formular, mesmo diante da tragédia mais clamorosa, uma resposta própria, isto é primária, e não apenas reagir de maneira circunstancial ou secundária". Assim, o texto literário não só reage aos fatos históricos, mas propõe novas visões sobre os acontecimentos; não está sujeito ao "teste da verificação nem se vale daquelas provas testemunhais que fornecem passaporte idôneo ao discurso historiográfico" (Bosi, 1995: 179).

Os modos de abordar a história podem ser reflexivos, sem deixar de ser divertidos, a partir do olhar armado de um poeta que procurou desmistificar o fazer histórico e cultural hegemônico. A literatura é, assim, um tipo de criatividade histórica contra o esquecimento cultural que vemos nas representações oficiais de nossa cultura.

\section{Referências bibliográficas}

BERGSON, Henri. 2001. O riso. Ensaio sobre a significação da comicidade. Trad. Ivone C. Benedetti. São Paulo: Martins Fontes.

BOSI, Alfredo.1995. Dialética da colonização. $3^{\mathrm{a}}$ ed. São Paulo: Companhia das Letras.

2000. O ser e o tempo na poesia. $6^{\text {a }}$ ed. São Paulo: Companhia das Letras.

2002. Literatura e resistência. São

Paulo: Companhia das Letras.

CARVALHO, José Murilo de. 1990. A formação das almas. O imaginário da república no Brasil. São Paulo:

Companhia das Letras.

CHARTIER, Roger. 2007. Entrevista: Roger Chartier. Nas entrelinhas do passado. Revista de História da Biblioteca
Nacional. Rio de Janeiro, ano 3, $\mathrm{n}^{\mathrm{0}} 28$, outubro.

CHAUÍ, Marilena. 2000. Brasil: mito fundador e sociedade autoritária. São Paulo: Fundação Perseu Abramo.

FAUSTO, Boris. 1985. A revolução de 30. In: MOTA, Carlos Guilherme (org.). Brasil em perspectiva. $15^{\mathrm{a}}$ ed. São Paulo: Difel.

GAY, Peter. 1990. O estilo na história. Trad. Denise Bottmann. São Paulo: Companhia das Letras.

GUIMARÃES, Júlio César Castañon. 1993. Territórios/conjunções: poesia e prosa crítica de Murilo Mendes. Rio de Janeiro: Imago.

INFANTE, Ulisses. 2003. 'O carioca passava a vida musicando' ou o carioca 
Murilo Mendes e a música popular urbana. Teresa Revista de Literatura Brasileira. São Paulo, ${ }^{\circ}$ 4/5.

LEMAIRE, Ria \& DE DECCA, Edgar Salvadori (orgs.). 2000. Pelas margens. Outros caminhos da história e da literatura. Campinas: Ed. Unicamp/Porto Alegre: Ed. da UFRGS.

MENDES, Murilo. 1994. Poesia e prosa completa. Luciana Stegagno Picchio (org.). Rio de Janeiro: Nova Aguilar.

MOURA, Murilo Marcondes de. 1998. Três poetas brasileiros e a Segunda Guerra Mundial (Drummond, Cecília Meireles e Murilo Mendes). São Paulo, USP, FFLCH (Tese de Doutorado).

OLIVEIRA, Cecília Helena de Salles. 2002. O Museu Paulista da USP e a memória da Independência. Cadernos CEDES, v. 22, n ${ }^{0}$ 58, dez. 2002.

Disponível em http:// www.scielo.br/pdf/ccedes/v22n58a05.pd f. Acesso em: 24/4/2008.

\& MATTOS, Claudia Valladão de. 1999. O Brado do Ipiranga. São Paulo: Edusp.

RANCIÈRE, Jacques. 2005. A partilha do sensivel. Estética e política. Trad. Mônica
Costa Netto. São Paulo: EXO experimental/ Editora 34.

SCHORSKE, Carl E. 2000. Pensar com a história. Indagação na passagem para o modernismo. São Paulo: Companhia das Letras.

SEVCENKO, Nicolau. 2003. A literatura como missão. $2^{\mathrm{a}}$ ed. São Paulo:

Companhia das Letras.

SKINNER, Quentin 2002. Hobbes e a teoria clássica do riso. Trad. Alessando Zir. São Leopoldo: Editora Unisinos.

SOUZA, Valmir de. 2006. Murilo Mendes: da história satírica à memória contemplativa. São Paulo, USP, FFLCH (Tese de Doutorado).

WHITE, Hayden. 1992. Meta-história: a imaginação histórica do século XIX. Trad. José Laurênio de Melo. São Paulo: Edusp.

Internet

http://www.escolavesper.com.br/indepen dencia_ou_morte.htm\#11

http://www.scielo.br/pdf/ccedes/v22n58a0 5.pdf.

\section{Resumo}

$\mathrm{O}$ artigo trata das relações da história com a literatura, estudo esse que aponta para a inter-relação de campos culturais distintos, mas que coloca também novas abordagens do fenômeno histórico. A literatura pode recontar a história estabelecida sob a ótica do autor satírico, fazendo com que através do riso se possam compreender os processos históricos, e dessacralizando versões cristalizadas da historiografia oficial. É nesse sentido que o diálogo entre literatura e história pode apontar para as tensões presentes na história e nas interpretações e representações do passado. São tomados como objeto de análise eventos da história do Brasil e as interpretações poéticas que deles faz o poeta Murilo Mendes.

Palavras-chave: história, literatura, Murilo Mendes, pintura, poesia 


\begin{abstract}
This paper is about the relation between history and literature. Besides the interaction between two distinct cultural areas, this kind of study can also indicate new approaches to historical phenomena. Literature can report official history from a satiric point of view, using the "laugh" to understand historical processes and to criticize dominant versions of history. In this sense the dialogue between literature and history can point out tensions in history and in the interpretations and representations of the past. Here we analyze events of Brazilian history and Murilo Mendes' poetical interpretations.
\end{abstract}

Key words: history, literature, Murilo Mendes, painting, poetry

\title{
Résumé
}

Cet article examine les rapports entre l'histoire et la littérature, un genre d'études qui s'intéresse à la relation entre deux champs culturels distincts, mais qui indique aussi de nouvelles possibilités d'approche du phénomène historique. La littérature peux raconter l'histoire du point de vue d'un auteur satirique, en nous permettant de comprendre les processus historiques par le rire, et en désacralisant les versions établies par l'historiographie officielle. C'est dans ce sens que le dialogue entre la littérature e l'histoire peut montrer les tensions qui existent dans l'histoire e dans les représentations du passé. On analyse ici quelques événements de l'histoire du Brésil et les interprétations qu'en a données le poète Murilo Mendes.

Mots-clés: histoire, littérature, Murilo Mendes, peinture, poésie 